\title{
Resenhas
}

\section{Ariadne da infância e do gênero: deslindando labirintos culturais}

\author{
Cultura, gênero e infância: nos \\ labirintos da história.
}

NASCIMENTO, Alcileide Cabral do; FARIA GRILLO, Maria Ângela de.

Recife: Editora Universitária UFPE, 2008. $282 \mathrm{p}$.

Publicar uma coletânea de artigos é amalgamar desejos e inquietações. Fruto de pesquisas e encontros do Grupo de Estudos em História Social e Cultural (GEHISC) sediado na Universidade Federal Rural de Pernambuco (UFRPE), o livro Cultura, gênero e infância: nos labirintos da história consolida a ideia de que pesquisas são necessariamente a combinação entre paixão, rigor teórico-metodológico e esforço coletivo de reflexão e debate. $O$ livro composto de 14 artigos e dividido em três partes abarca diferentes aspectos e olhares sobre 0 universo da cultura, gênero e infância.

Na primeira parte, "Cultura e cidade", três autores dão conta do entendimento dos espaços urbanos como lugares de experiências humanas e de grupos heterogêneos que disputam constantemente espaços e poder. As cidades são percebidas como invenções sociais, pois se constituem e se representam através das relações entre o homem e a natureza, a concretude do ambiente visível e as sensibilidades sutis que se constroem no trânsito dos sujeitos nos espaços.

O texto de Durval Albuquerque vem, em uma defesa apaixonada da Nova História Cultural, reiterar a necessidade de um novo olhar para os saberes e duplos do conhecimento histórico, as brechas na teia de Ariadne, que a História tradicional acreditava serem fiapos sem relevância na trama. Ao analisar o livro de José Saramago O homem duplicado,' o autor tece uma série de considerações e questionamentos epistemológicos da Historiografia brasileira. As subjetividades, os novos métodos e as novas questões mostram que a renovação trazida pela História Cultural é fundamental para o escrutínio de novas e antigas fontes e para interpretações diversas, cujos duplos de si trarão sempre a possibilidade de novas investigações. No tom efervescente e conciso das palavras, $o$ autor instiga e desafia o leitor a buscar na trama do passado respostas, que sempre serão novas perguntas, no desafio axiológico da pósmodernidade.

Os caminhos da Rua Nova no centro de Recife em 1920 e seus transeuntes peculiares surgem na escrita do artigo de Sylvia Costa Couceiro. O espaço urbano se revela como propõe Richard Sennet em Carne e pedra, ${ }^{2}$ constituído de cimento e sangue, singrando entre os muros e o asfalto. A Rua Nova de origem velha do século XVIII encarna o símbolo de uma população que almejava o progresso, a esperança e as mudanças da modernidade. À narrativa histórica mescla-se boa dose de lirismo e criatividade. Personagens são compostos e recompostos no cenário urbano, e o leitor embarca nas páginas de uma divertida narração/análise das figuras, hábitos e costumes que frequentavam a Rua Nova. No entanto, tal recurso narrativo não diminui o compromisso com o rigor teórico-metodológico e uma minuciosa pesquisa de diversas fontes. Na cena urbana moderna personagens circulam pelo espaço como num palco: querem observar e serem observados. A rua é, como bem sintetiza Walter Benjamin, "as vitrines da modernidade". ${ }^{3}$

Para pensar essa modernização e seu caráter excludente e hierárquico, $\mathrm{o}$ artigo de Luís Manuel Domingues do Nascimento traz à baila os sacrifícios que a cidade de Recife sofre na década de 70 do século $X X$, ao custo de um discurso modernizador do espaço urbano. Para o autor, condensada ao discurso do progresso, Recife expandiu-se sob a égide de uma lógica que nega sua memória e suas experiências históricas. A crítica assume tom de denúncia ao analisar os problemas e deficiências conse- 
quentes dessa modernização, em especial com relação à burocratização e tecnocratização das autoridades e ao aumento das favelas e classes baixas dependentes de um sistema administrativo incapaz de solucionar as crises instaladas nas áreas públicas da saúde, moradia e educação.

Em "Representações, cultura política e sexualidade na seara dos gêneros" reverberam as imagens sociais e culturais de Pernambuco. Personagens e linguagens típicos consolidados no imaginário nacional - como a literatura de cordel e o cangaceiro - são perscrutinados em análises atentas às construções históricas de múltiplas representações, à diversidade de discursos e às possibilidades de interpenetrações na construção das narrativas históricas.

Maria Ângela de Faria Grillo apresenta de maneira bastante didática inicialmente uma breve retrospectiva historiográfica de importantes estudos realizados no campo de gênero, para então expor sua análise das representações construídas sobre o homem e a mulher, e suas relações na literatura de cordel na primeira metade do século $X X$.

A dificuldade em lidar com as transformações do mundo moderno tendem a cristalizar o papel da mulher dona de casa/mãe ao mesmo tempo que revelam as novas situações e valores sociais. Regras sobre casamento, imagens de Eva e Maria e lições de comportamento, preconceitos e ambiguidades da época transparecem no estudo historiográfico dos versos de cordel. Imagens e representações femininas como peças-chave para a compreensão de determinados modelos e costumes sociais, a literatura de cordel é o manancial de estudo fortemente pesquisado por Grillo.

Antonio Silvino é a figura explorada através dos jornais no artigo de Rômulo José $\mathrm{F}$. de Oliveira Junior. Cangaceiro, prisioneiro a maior parte de sua vida, "macho nordestino"... as representações em torno do masculino constroem-se a partir de um personagem sólito e presente no imaginário popular pernambucano, ratificando modelos e convenções da sociedade. Homem fora da lei e ao mesmo tempo preocupado com a aparência e a elegância, Antonio Silvino foi alvo de intensos debates na imprensa, cujo discurso é esmiuçado e interpretado detalhadamente pelo autor.

As imagens de ser masculino do sertão nordestino são acompanhadas em seguida pela "Cultura da beleza: práticas e representações do embelezamento feminino", de Natália Conceição Silva Barros. A autora levanta importantes questões, alicerçada em fontes valorizadas pela História Cultural, tais como revistas, jornais, memórias e obras literárias. Ao longo do texto busca compreender as maneiras como as recifenses e os recifenses reconheciam, controlavam e moldavam seus corpos entendidos aqui como um território "biocultural", onde as relações de poder entre os gêneros feminino e masculino se explicitam em um campo de forças diferenciado nos discursos sobre a beleza e o embelezamento dos corpos.

$O$ culto à beleza e o consumo de produtos que realçariam e/ou consertariam traços de fealdade fizeram parte das estratégias do mercado e da modernização dos hábitos e costumes da época.

Saindo dos anos 20, o leitor embarca em uma Recife feminina insurgente dos anos prégolpe militar entre 1960 e 1964. Juliana Rodrigues de Lima Lucena investiga a intelectualidade feminina através de três eminentes figuras pouco ou nada lembradas pela historiografia tradicional: Anita Paes Barreto, do Movimento de Cultura Popular; Geninha da Rosa Borges e Diná de Oliveira, do Teatro de Amadores de Pernambuco. Os movimentos artísticos e intelectuais que surgiram na época, a partir das discussões sobre novas ideias e modelos sobre cidadania e sociedade, tinham o intuito tanto de atingir uma parcela marginalizada da população quanto de criar uma atmosfera propícia a uma remodelação social com a inclusão na vida política dessa parcela da população.

O último artigo dessa segunda parte da coletânea lida com uma questão da História do tempo "recentíssimo": a violência e a intolerância contra mulheres, adolescentes e crianças exploradas sexualmente no município de Serra Talhada no século XXI. Os registros de estupro, de lesões corporais, deformações e homicídios na região entre 2004 e 2006 são uma marca que, embora alarmante, não mobilizou ainda o suficiente o poder público para criar na região, por exemplo, uma delegacia feminina. Esse artigo denuncia uma situação insustentável nos tempos atuais que demonstra a permanência de discursos sexistas, preconceituosos e homofóbicos, além de perigosas práticas de violência cuja legitimidade se encontra em representações incrustadas socialmente - dados vultosos de uma realidade violenta cuja luta por mudanças passa necessariamente pela denúncia, discussão e mobilização para o exercício da tolerância e do respeito ao Outro.

Na última parte do livro, "Infâncias, histórias e rebeldias em Pernambuco", a atenção é 
voltada para a infância. Enjeitados, trabalho de rua e doméstico e o cotidiano infantil são os temas de pesquisa presentes. Através de uma Pernambuco criança, percebida no limiar entre a ordem e a transgressão, os artigos demonstram os espaços de inserção e de exclusão da criança bem como as diversas políticas sociais em torno da infância desenvolvidas no Estado. Ressalto que, nesse momento da coletânea, a presença de Alcileide Cabral do Nascimento pode ser amplamente observada. Dos seis artigos a autora assina a coautoria de mais quatro trabalhos, além de seu próprio trabalho que abre essa terceira parte. Apenas o último artigo, de Humberto Miranda, não conta com a colaboração de Alcileide. Tais trabalhos podem ser interpretados como desdobramentos de um esforço coletivo de pensar a temática da infância, violência, rejeição, abandono e estratégias do Estado e da sociedade, ao longo da história de Pernambuco, para conformar e disciplinar essa população pobre, órfã e marginalizada.

Intolerância, rejeição e abandono. O final da segunda parte da obra consegue se articular perfeitamente, e infelizmente - uma vez que as permanências de uma zona sombria e tortuosa de nossa história social e cultural se evidenciam -, com o primeiro artigo da terceira parte. "A Roda dos Enjeitados" é cenário do trabalho de Alcileide Cabral do Nascimento sobre as práticas de infanticídio e/ou esquecimento dos nascimentos não desejados. O discurso legitimador da roda encontra raízes na manutenção da ordem social, encobrindo, por exemplo, atitudes que depusessem contra a honra de "moças de famílias honestas ludibriadas" ou tentadas pelos "pecados da carne"; os casos de pobreza extrema; as doenças; a viuvez e seus impedimentos morais; a loucura e/ou a prisão e seus impedimentos sociais.

Quaisquer que fossem os motivos, a Roda dos Enjeitados chancelou os desvios do padrão social constituído na ordem colonial. Qual o destino dessas crianças? De que maneira inserilas socialmente? São as questões do artigo de Rose Kelly Correia de Brito, que analisa os mecanismos pelos quais o Estado, entre 1831 e 1860 , buscou disciplinar, controlar e conformar as meninas pobres enjeitadas e órfãs do Recife. A educação elementar e o trabalho doméstico são comumente vistos como caminhos possíveis de utilidade social dessa população cujo destino parecia preocupar as autoridades, dada sua potencialidade perigosa, caso permanecesse à margem da sociedade. Conformadas ao lar e aos trabalhos domésticos, as moças eram disciplinadas dentro dos parâmetros sociais aceitáveis ao mesmo tempo que isso lhes garantia um meio de sustento, o que desoneraria o Estado. Entre os obstáculos ressaltados sobre esse projeto estavam a própria lentidão e burocracia do Estado em criar condições efetivas para a educação dessas moças, além do preconceito e repúdio das famílias em pagar por serviços que poderiam explorar das escravas. A questão racial interferiu, inclusive, na condução dos mecanismos de controle em cercear a vida social, na qual mulheres brancas tiveram claras vantagens em relação ao tratamento dispensado às mulheres pardas e negras.

Os dois artigos subsequentes, de autorias respectivas de Hugo Coelho Vieira e Wandoberto Francisco, abordam as maneiras como o Arsenal de Guerra de Pernambuco e o Arsenal da Marinha do Recife serviram como espaço de serviços educacionais e militares para populações de órfãos, pobres e renegados em meados do século XIX. Remontando à genealogia desses locais, os autores seguem a trilha da expansão desses trens militares, que inicialmente serviriam apenas como aparatos burocráticos de armazenamento de materiais, e cujas funções e ofícios aumentaram historicamente, conforme a demanda de serviços da cidade e dos materiais de guerra. A formação, o tratamento dispensado no processo educativo e as interdições sociais compõem um cenário de lutas e contradições entre o discurso dessas instituições e a realidade dispensada a essas populações.

Wendell Rodrigues Costa preocupou-se com a formação e a inserção social de meninos e jovens pobres, enjeitados e escravos no mercado de trabalho urbano em Recife no século XIX. A prática de aprendiz aparece como uma estratégia política de combate à criminalidade. Aprender um ofício afastaria esses jovens da ociosidade e da possível marginalidade. A instrução desses moços era feita em espaços escolares permeados pela discriminação de cor e status social, onde, por exemplo, a cobrança de taxas de matrícula ou excluía as camadas mais pobres do acesso à educação, ou instituía a prática do "apadrinhamento", o que reforçava a ordem social marcada por privilégios.

Através desses três artigos, pode-se perceber que estudar no Brasil dependia da condição social das famílias e que os estabelecimentos destinados a aprendizes pobres sofriam com um menor auxílio e aparato do governo.

Humberto Miranda fecha a terceira parte dessa coletânea pensando o cotidiano dos

Estudos Feministas, Florianópolis, 18(2): 607-623, maio-agosto/2010 609 
meninos confinados em instituições supostamente correcionais de Recife entre 1927 e 1937. Entre os abusos e transgressões cometidas pelos agentes penitenciários da Casa de Detenção e a modernização desse espaço no início do século XX com a criação, em 1932, do Instituto Profissional 5 de Julho, posteriormente chamado de Abrigo de Menores, buscou-se ressocializar e mesmo curar tais crianças através dos mesmos mecanismos vistos nos demais artigos dessa parte: estudos profissionalizantes, que seriam para o governo a resposta para a inserção social desse grupo marginal.

Há uma triste conclusão histórica ao final dessa leitura: a pobreza sofre duplamente, tanto pela sua condição cotidiana quanto pelo tratamento preconceituoso dispensado pelas autoridades encarregadas em lidar com as estratégias que deveriam diminuir e mesmo sanar essa questão social.

É preciso ressaltar que toda publicação possui as limitações da materialidade. O livro não inclui, por exemplo, questões sobre as representações da maternidade - fundamentais nas discussões de gênero e infância-, pois, se o fizesse, certamente $\circ$ volume de páginas acabaria por inviabilizar sua publicação. A árdua tarefa de edição não pode prescindir de cortes e moldes. Cabe escolher e esculpir a obra com sentido e sentimento. Não obstante, apresentando ao público leitor a consistência e seriedade das pesquisas desenvolvidas pelo GEHISC, as organizadoras tranquilizam-no com a promessa de "gestação" de mais frutos dessa seara. E assim o primogênito desse grupo, Cultura, gênero e infância..., nasceu sob o prisma das interrelações entre cidades, representações femininas e masculinas e o mundo infantil.

Alcileide Cabral do Nascimento e Maria Ângela de Faria Grillo, organizadoras do livro, desejam que "o leitor se perca e se encontre nos labirintos da história e da beleza de compreender os duplos de si" (p. 9). Esse livro permite que os duplos se transformem em múltiplos significados nas possibilidades de compreensão de falas e silêncios, cujas marcas são sensíveis às narrativas das pesquisas contidas na obra.

\section{Notas}

I SARAMAGO, 2002.

2 SENNET, 2001.

${ }^{3}$ BENJAMIN, 1975.

\section{Referências bibliográficas}

BENJAMIN, Walter. A modernidade e os modernos. Rio de Janeiro: Tempo Brasileiro, 1975.

SARAMAGO, José. O homem duplicado. São Paulo: Companhia das letras, 2002.

SENNET, Richard. Carne e pedra: o corpo e a cidade na civilização ocidental. Rio de Janeiro: Record, 2001.

Ana Carolina Eiras Coelho Soares Universidade Federal de Goiás 